\title{
Imaging the Lithosphere-Asthenosphere Boundary (LAB) under Brazil
}

\author{
Carolina Rivadeneyra-Vera ${ }^{1}$, Marcelo Bianchi ${ }^{1}$
}

('Instituto de Astronomia, Geofísica e Ciências Atmosféricas/USP, Brazil)

\section{Copyright 2021, SBGf - Sociedade Brasileira de Geofísica}

This paper was prepared for presentation during the $17^{\text {th }}$ International Congress of the Brazilian Geophysical Society held in Rio de Janeiro, Brazil, 16-19 August 2021.

Contents of this paper were reviewed by the Technical Committee of the $17^{\text {th }}$ International Congress of the Brazilian Geophysical Society and do not necessarily represent any position of the SBGf, its officers or members. Electronic reproduction or storage of any part of this paper for commercial purposes without the written consent of the Brazilian Geophysical Society is prohibited.

\begin{abstract}
Using the S-wave receiver function (SRF) method and teleseismic data from many stations of the Permanent Brazilian Network (RSBR) and XC temporary deployment, we studied the Lithosphere-Asthenosphere Boundary $(\mathrm{LAB})$ in the most part of the South American platform. At the Borborema and Mantiqueira Provinces we confirmed a thinner lithosphere of $\sim 90 \mathrm{~km}$, that also characterizes the Chaco and Pantanal Basins. Amazon Craton, São Francisco Craton, and Paranapanema block present a thicker lithosphere, greater than $120 \mathrm{~km}$; in these older and colder areas we also found a mid-lithospheric discontinuity (MLD) at $\sim 90 \mathrm{~km}$, which tends to correlate with the heat flow. Nevertheless, we do not observe a clear correlation between the heat flow and deeper LAB measurements.
\end{abstract}

\section{Introduction}

The $L A B$ is a first-order structural change that separates the outermost rigid, cold, mechanically strong, and conductive lithosphere from the ductile, weak, and convective asthenosphere (Sun et al., 2018), its study is fundamental for understanding the processes of continental evolution and interaction with plate tectonics. The lithosphere comprises the crust and uppermost mantle (Marshak and Van Der Pluijm, 2004; Fowler, 2005; O'Reilly and Griffin, 2010).

The estimated LAB depth varies according to the property considered (e.g. elastic, thermal, electrical, petrological, and seismic velocities), being the seismological LAB, associated with a low-velocity zone in the upper mantle, normally deeper than other ones. Between seismological methods, surface-wave tomography provides robust constraints about lithospheric structure, nevertheless it cannot distinguish if a velocity change is abrupt or occurs over tens of kilometers (Fischer et al., 2010). On the other hand, the high frequencies used in body-wave tomographies do not permit the detection of the LAB if it is not sharp enough (Rychert and Shearer, 2009).

The S-wave receiver function method provides powerful complementary constraints of the LAB and its velocity gradient, being its converted phases sensitive to changes in shear-wave structure. It was proposed for the first time by Farra and Vinnik (2000), and subsequently Yuan et al. (2006) and Kind et al. (2012) provided more details of the technique, being carried out successfully to estimate the LAB depth over the world (Kumar et al., 2005; Yuan et al., 2006; Kumar et al., 2007; Hansen et al., 2009; Kumar et al., 2012; Blanco et al., 2017). Although several studies map the LAB on a global scale (Rychert and Shearer, 2009; Pasyanos et al., 2014; Priestley et al., 2018), the South American LAB has been poorly studied because of the lack of seismic stations until a few years ago, and the large amount of data required (Bianchi, 2008). Due to the geographic location of South America and distances/magnitude requirements for the method, a database of several years is needed. On average a station will record $\sim 25$ events per year only.

Despite these limitations, Heit et al. (2007) estimated the $\mathrm{LAB}$ depth under some South American stations finding a notably thicker lithosphere (up to $160 \mathrm{~km}$ ) under cratonic and surroundings areas, and a thinner one under coastal areas (passive continent-ocean margin).

The main focus of this work is to present an updated initial estimate of the LAB thicknesses under the South, West and Central Brazillian platform, establishing correlations with the heat flow measurements.

\section{Method}

We analyzed the RSBR and some international stations from 2010 to 2019 , XC temporary deployment from the middle of 2016 to 2020; considering events of magnitude greater than $5.8 \mathrm{mb}$ and epicentral distances between $65^{\circ}$ and $85^{\circ}$ (Yuan et al., 2006; Heit et al., 2007), as shown in Figure 1.

Each selected seismogram was windowed 300 seconds before and 100 seconds after the S-wave arrival, rotated into ZRT using the back azimuth angle, and finally to LQT coordinate system, considering the theoretical incidence angle according to IASP91 model (Kennett and Engdahl, 1991). Rotated traces were detrended and filtered between 1.5 and $0.01 \mathrm{~Hz}$, finally they were deconvolved, mirrored and cutted between 20 seconds before and 150 seconds after $t=0$. The SRF traces were visually inspected to do quality control and were discarded the noisy and unstable ones.

As every event has different source parameters, it is necessary to do a move-out correction to a reference value of $6.4 \mathrm{~s} /{ }^{\circ}$. Because of the low signal-to-noise ratio of SRF traces, it is necessary to stack several events to enhance the signal of $\mathrm{Sp}$ conversion at LAB. Corrected traces were stacked and filtered by a low-pass 6 seconds. A final bootstrap of 100 resamplings were used to estimate the uncertainties. 


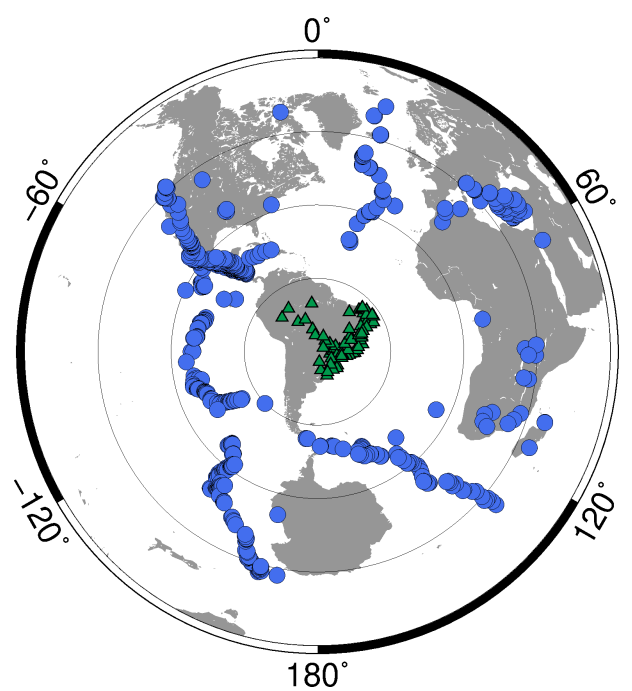

Figure 1: Distribution of events used in S-wave receiver function analysis. Blue circles: events selected, green triangles: seismic stations. Concentric circles are distances every $30^{\circ}$.

The arrival time of Sp conversion at LAB is obtained from the minimum position of the SRF trace that later is converted to depth using the IASP91 model (Kennett and Engdahl, 1991). Since we bootstrap the stacks, we assume the median of the estimates as the lithosphere thickness and the standard deviation as the uncertainty.

\section{Results and discussions}

The estimated lithospheric thickness in the South American platform is shown in Figure 2, where the size of the circles are according to the uncertainty of the estimate: Biggest circles have uncertainties smaller than $10 \mathrm{~km}$, and smallest ones present an uncertainty greater than $20 \mathrm{~km}$. We confirmed a thinner lithosphere of $\sim 80 \mathrm{~km}$ at Borborema Province, observed previously by Heit et al. (2007) analyzing one international station, here we processed more than 10 stations, all with consistent results. Along the continent-ocean margin, at Mantiqueira Province, we found a $L A B$ about $\sim 90 \mathrm{~km}$, being thicker in stations close to the São Francisco Craton, that could indicate an extension of the craton toward the south along the coastal part.

Most stations located in the São Francisco craton present a lithospheric thickness of $\sim 150 \mathrm{~km}$, being shallower $(\sim 100 \mathrm{~km})$ in some stations close to its borders, mainly along the coast.

In the Amazon Craton that includes the Central Brazilian Shield (CBS) and Amazon Basin (Am), we observe a thicker lithosphere up to $200 \mathrm{~km}$, in agreement with the oldest cratonic areas of the world. The lithosphere sharply refines toward Pantanal and Chaco Basins that reach depths up to $100 \mathrm{~km}$. The Paraná Basin presents a thinner lithosphere of $\sim 100 \mathrm{~km}$ at some stations, and thicker one at Paranapanema cratonic block and in the south-western part of the basin.

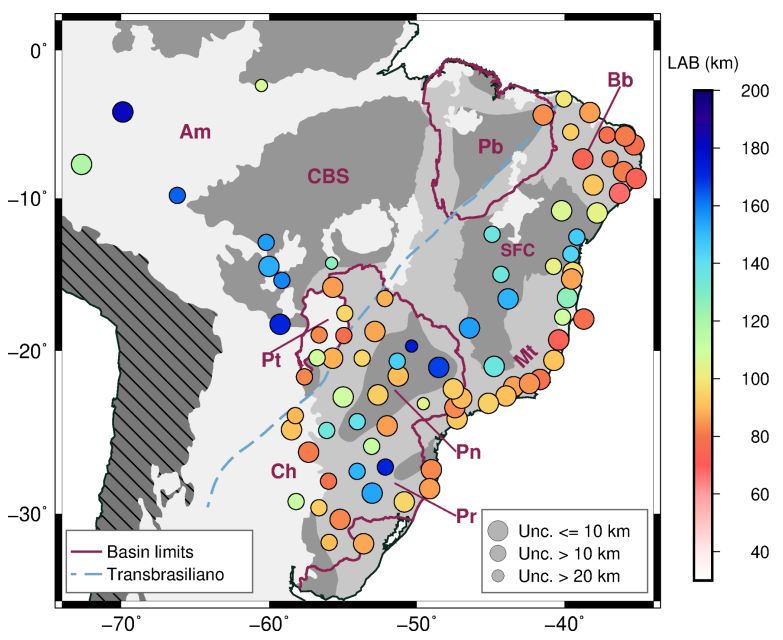

Figure 2: Lithospheric thickness map in Central South America, the size of circles represent the uncertainty of each estimation. CBS: Central Brazilian Shield, Pn: Paranapanema Cratonic Block, SFC: São Francisco Craton, Mt: Mantiqueira Province, Bb: Borborema Province, Ch: Chaco Basin, Am: Amazon Basin. Purple line delimits the basins: Paraná (Pr), Parnaiba $(P b)$ and Pantanal (Pt). Light blue dotted line: Transbrasiliano Lineament.

Most of the stations in cratonic areas present a first negative arrival at $\sim 10$ seconds $(\sim 100 \mathrm{~km})$, which seems to fit with a second-order mid-lithospheric discontinuity (MLD) between the Moho and the LAB, widely reported in cratonic areas (Rychert and Shearer, 2009; Fischer et al., 2010; Yuan and Romanowicz, 2018; Priestley et al., 2018; Kind and Yuan, 2018; Sun et al., 2018). This discontinuity would correspond to the base of the most chemically depleted layer indicated by xenoliths (Fischer et al., 2010; O'Reilly and Griffin, 2010). When two negative arrivals were observed, the second one was interpreted as the LAB, according to Fischer et al. (2010), as shown by Figure 3.
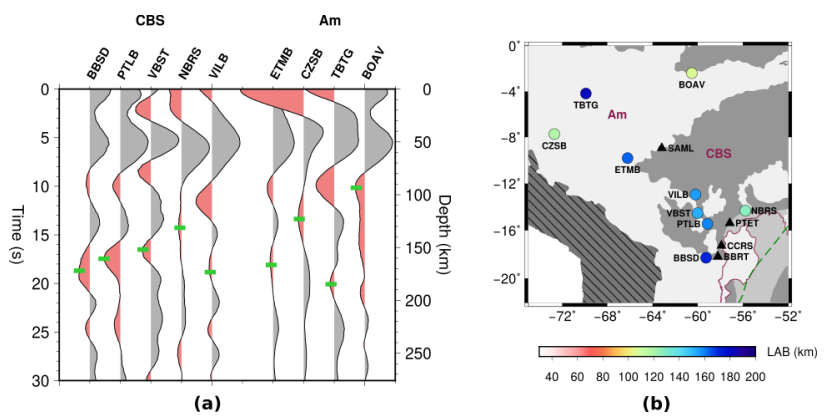

(b)

Figure 3: (a) SRF section for Amazon Craton, grouped in Central Brazilian Shield (CBS) and Amazon Basin (Am), green marks show $L A B$ phases. (b) Lithospheric thickness map for the Amazon Craton.

Mantle heat flow reflects the thermal structure, evolution, and geochemistry of the lithosphere being somehow correlated with its thickness. Considering the world heat 
flow compilation presented by Davies (2013), we observed that areas with greater heat flow present a thinner lithosphere, such as Borborema, most of Mantiqueira Province, and Pantanal Basin. On the other hand, cratonic colder and older areas, such as Amazon, São Francisco Craton, and Paranapanema block, also present a deeper LAB (Figure 4).

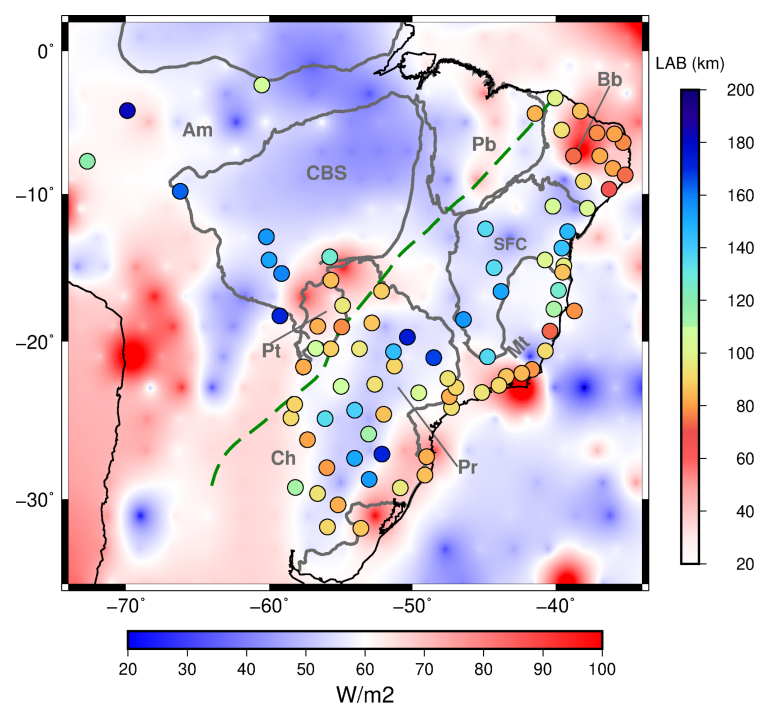

Figure 4: Heat flow (Davies, 2013) vs lithospheric thickness. Grey line delimits main geological provinces, Am: Amazonian Basin, CBS: Central Brazilian Shield, Pt: Pantanal Basin, Pr: Paraná Basin, Ch: Chaco Basin, SFC: São Francisco Craton, Pb: Parnaíba Basin, Mt: Mantiqueira Province and Bb: Borborema Province. Green dotted line: Transbrasiliano Lineament.

In cratonic areas, where the LAB depth was estimated about $\sim 100 \mathrm{~km}$, it is possible that we misinterpreted the $L A B$ with MLD, if this lithospheric discontinuity is related to a migration of partial melting, as proposed by Fischer et al. (2010), it is expected that these areas present greater values of heat flow, which is not observed in Figure 4. In Addition to the manual readings presented in Figure 2 and 4, we prepared a second set of automatic measurements, with the objective of not being biased by the interpreter. The automatic procedure searched for the largest negative peak between 0 and 20s. Those time values were converted to depth, and Figure 5 presents a plot of heat flow versus automatic measurements, where we can observe that, to some degree, part of the measurements are linearly correlated.

We made a linear regression between the heat flow and lithospheric thickness from automatic reads, remembering that the highest negative arrival could be the MLD or LAB, as interpreted in the manual set. The regression only considered lithospheric thicknesses smaller than $\sim 130$ $\mathrm{km}$, area below the dotted line in Figure 5, and indicates a linear trend between the values. Despite the low correlation coefficient $(0.32)$, the residuals tend to have a normal distribution, indicating that the observed variations can be due to noise measurements or other non-systematic fluctuations in the observed values.

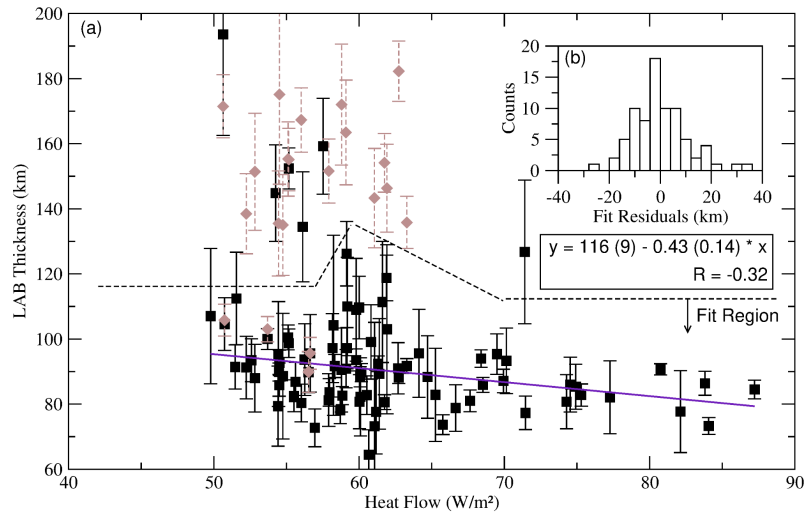

Figure 5: Heat flow and lithospheric thickness correlation. Black squares: automatic dataset. Brown diamonds: manual readings that have different values than the automatic dataset. Purple line: linear regression of the automatic dataset for the points inside the fit region. Picture embedded: histogram of the regression residuals.

From Figure 5, we see that the SRF traces showing double negative phases are located in regions of low heat flow $\left(<65 \mathrm{~W} / \mathrm{m}^{2}\right)$, even for the automatic measurements. Another way to interpret the data presented by this figure is that both readings are showing different features, and they should not be mixed. The first, shallower, and mostly clear negative conversion should be interpreted as the MLD; and the second and deeper conversion should be attributed to the $L A B$. While for regions with higher heat flow the $L A B$ is not observable, probably because the velocity structure of the lithosphere does not permit that the low-velocity transition from the LAB be evident anymore, being clear only the low-velocity transition associated to the MLD, that is reinforced by the high heat flow and melt migration or other compositional processes.

A schematic diagram for this idea is presented in Figure 6 , where we reinforce the idea that the high heat flow changes the velocity structure of the upper mantle (reducing the velocity of the lithosphere as a whole) making impossible the detection of the LAB by the SRF; in these cases, the only negative arrival should be attributed to the proposed MLD. It is clear that while SRF alone will not be able to resolve this problem, the MLD or another low-velocity discontinuity should be proposed to explain the observed data. Meanwhile, the seismological LAB continues as an important matter in the frontier of the seismological methods, while our results indicate that it is present in some cratonic regions and absent (or not detectable) in high heat flow areas. On the other hand, the MLD is present in all regions and shows a trend with the observable heat flow values. Finally, we don't observe any trend with $L A B$ depth and heat flow in cratonic and older regions. 
Lithosphere-Asthenosphere Boundary UNDER BRAZIL

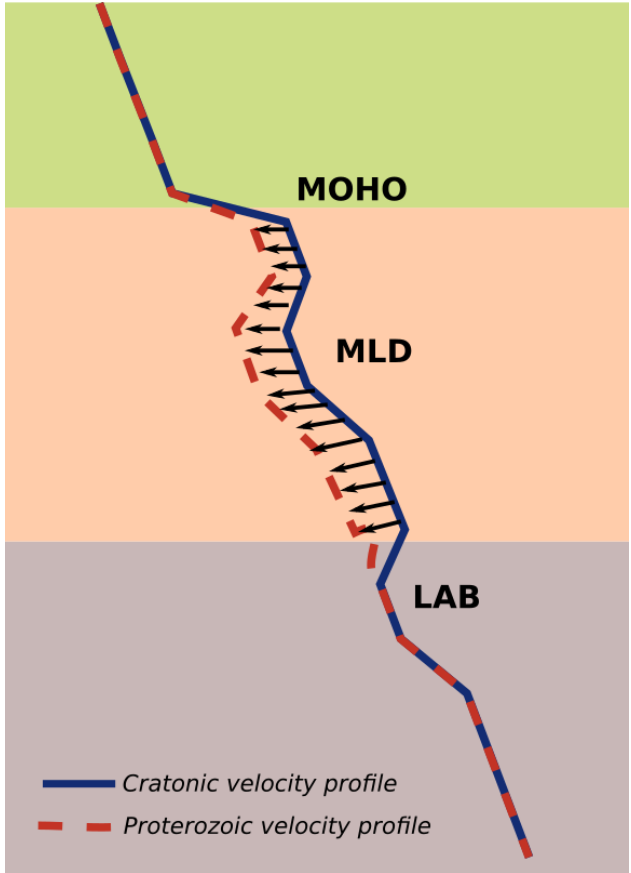

Figure 6: Schema for lithosphere structure in areas with lower and higher heat flow. For colder lithosphere the phase conversion at the $L A B$ is stronger, while at hotter areas this conversion tends to be weaker, being not noticeable at SRF.

\section{Conclusions}

Our LAB depth estimate tends to vary with the tectonic units. We confirmed a thinner lithosphere of $\sim 80 \mathrm{~km}$ at Borborema Province and near the passive margin area of the Mantiqueira Province; both of them studied before using only one station. Marginal stations part of the São Francisco Craton presented a thicker lithosphere. In the Amazon region the thicker lithosphere reaches values up to $\sim 180 \mathrm{~km}$, thinning to Pantanal Basin. Finally, Paraná Basin is characterized by an average lithosphere thickness of $\sim 120 \mathrm{~km}$, being notably thicker in the southeastern part of the basin and in the Paranapanema cratonic block.

In cratonic and older areas we have observed two negative arrivals, interpreting the first one as the MLD which presents an average depth of $\sim 90 \mathrm{~km}$, and the second one as the deeper LAB. Nevertheless, there does not seem to be a clear correlation between the heat flow and MLD and LAB together. We believe that in areas with higher heat flow the lithospheric mantle shows a lower velocity contrast at the $L A B$, which disappears from the SRF traces.

The S-wave receiver function method can resolve discontinuities at a lithospheric scale, but it needs a good quantity of data due to the weaker characteristics of the signal, which could be misinterpreted due to the presence of noise. We recommend at least three years of data at each station located in the South American continent.

\section{Acknowledgments}

We thank CNPq and CAPES for a PhD scholarship. We thank the members of the Brazilian Seismographic Network (RSBR). the FAPESP and the "3-Basins Project Team" that made possible the production of our data set. Finally, we would like to thank the Institute of Astronomy, Geophysics and Atmospheric Science for providing the infrastructure and resources for the development of this work.

\section{References}

Bianchi M. B. d., Variações da estrutura da crosta, litosfera e manto para a plataforma Sul Americana através de funções do receptor para ondas $P$ e $S$, Universidade de São Paulo, 2008, Ph.D. Thesis

Blanco J. F., Vargas C. A., Monsalve G., Lithospheric thickness estimation beneath North-western South America from an S-wave receiver function analysis, Geochemistry, Geophysics, Geosystems, 2017, vol. 18, p. 1376

Davies J. H., Global map of solid Earth surface heat flow, Geochemistry, Geophysics,Geosystems, 2013, vol. 14, p. 4608

Farra V., Vinnik L., Upper mantle stratification by P and S receiver functions, Geophysical Journal International, 2000, vol. 141, p. 699

Fischer K. M., Ford H. A., Abt D. L., Rychert C. A., The lithosphere-asthenosphere boundary, Annual Review of Earth and Planetary Sciences, 2010, vol. 38, p. 551

Fowler C. M. R., The Solid Earth: An introduction to Global Geophysics second edition edn. Cambridge University Press, 2005

Hansen S., Nyblade A. A., Julia J., Estimates of crustal and lithospheric thickness in Sub-Saharan Africa from S-wave receiver functions, South African Journal of Geology, 2009, vol. 112, p. 229

Heit B., Sodoudi F., Yuan X., Bianchi M., Kind R., An S receiver function analysis of the lithospheric structure in South America, Geophysical Research Letters, 2007, vol. 34

Kennett B. L. N., Engdahl E., Traveltimes for global earthquake location and phases identification, Geophysical Journal International, 1991, vol. 105, p. 429

Kind R., Yuan X., Kumar P., Seismic receiver functions and the lithosphere-asthenosphere boundary, Tectonophysics, 2012, vol. 536, p. 25

Kind R., Yuan X., , 2018 in , Lithospheric Discontinuities. John Wiley \& Sons pp 139-154

Kumar P., Kind R., Hanka W., Wylegalla K., Reigber C., Yuan X., Woelbern I., Schwintzer P., Fleming K., Dahl-Jensen T., et al., The lithosphere-asthenosphere boundary in the North-West Atlantic region, Earth and Planetary Science Letters, 2005, vol. 236, p. 249 
Kumar P., Kind R., Priestley K., Dahl-Jensen T., Crustal structure of Iceland and Greenland from receiver function studies, Journal of Geophysical Research: Solid Earth, 2007, vol. 112

Kumar P., Kind R., Yuan X., Mechie J., USArray receiver function images of the lithosphere-asthenosphere boundary, Seismological Research Letters, 2012, vol. 83, p. 486

Marshak S., Van Der Pluijm B. A., Earth structure: An introduction to structural geology and tectonics. WW Norton, 2004

O'Reilly S. Y., Griffin W. L., The continental lithosphere-asthenosphere boundary: can we sample it?, Lithos, 2010, vol. 120

Pasyanos M. E., Masters T. G., Laske G., Ma Z., LITHO1. 0 : An updated crust and lithospheric model of the Earth, Journal of Geophysical Research: Solid Earth, 2014, vol. 119 , p. 2153

Priestley K., McKenzie D., Ho T., , 2018 in , Lithospheric Discontinuities. John Wiley \& Sons pp 111-124

Rychert C. A., Shearer P. M., A global view of the lithosphere-asthenosphere boundary, Science, 2009, vol. 324, p. 495

Sun D., Tan E., Helmberger D., Gurnis M., Seismological support for the metastable superplume model, sharp features, and phase changes within the lower mantle, Proceedings of the National Academy of Sciences, 2007, vol. 104, p. 9151

Yuan X., Kind R., Li X., Wang R., The $S$ receiver functions: synthetics and data example, Geophysical Journal International, 2006, vol. 165, p. 555

Yuan H., Romanowicz B., , 2018 in , Lithospheric

Discontinuities. John Wiley \& Sons pp 1-4 